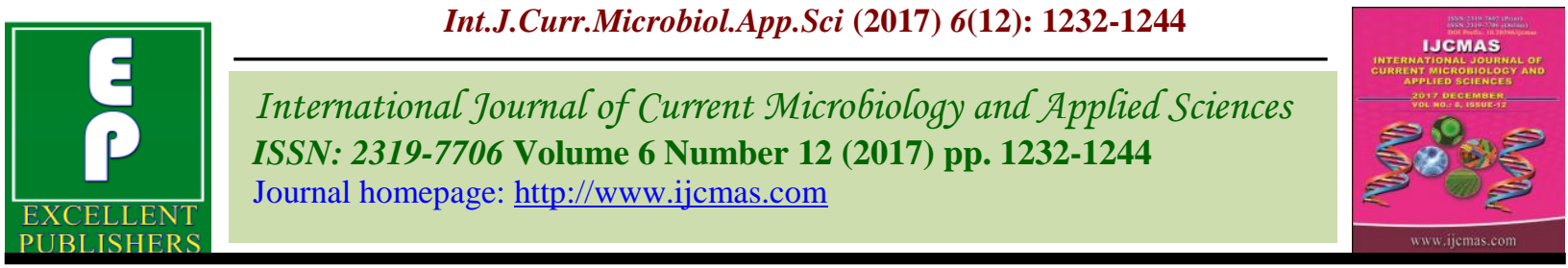

Review Article

https://doi.org/10.20546/ijcmas.2017.612.139

\title{
Weed Management Options in Conservation Agriculture
}

\author{
Twinkle Jena ${ }^{1 *}$ and Babu Lal Meena ${ }^{2}$ \\ ${ }^{1}$ Department of Agronomy, Institute of Agricultural Sciences, Banaras Hindu University, \\ Varanasi, UP-221005, India \\ ${ }^{2}$ Department of Agronomy, College of Agriculture, Lalsot (Dausa), SKNAU, Jobner, Jaipur, \\ Rajasthan-303511, India \\ *Corresponding author
}

A B S T R A C T

\begin{tabular}{|l|}
\hline Ke y w or d s \\
$\begin{array}{l}\text { Conservation } \\
\text { agriculture, Weeds, } \\
\text { herbicides, Residue, } \\
\text { Weed control. }\end{array}$ \\
\hline Article Info \\
\hline $\begin{array}{l}\text { Accepted: } \\
10 \text { October } 2017 \\
\text { Available Online: } \\
10 \text { December } 2017\end{array}$ \\
\hline
\end{tabular}

\section{Introduction}

Conservation agriculture (CA) is an agricultural management practice which includes minimum soil disturbance, retention of residue for soil cover and rotation of crops in its simplest form (Hobbs et al., 2008). In contrast, traditional agriculture practices involve intensive tillage operation for the preparation of fine and well pulverized seed bed, clean cultivation involving removal or burning of all residues after harvesting to the loss of nutrient from the soil profile, bare soil with no cover which facilitates the loss of moisture from soil surface. It also involves indiscriminate and excessive use of agrochemicals like fertilizer and pesticides which is responsible for reduction in input use efficiency, factor productivity and environmental pollution. Conservation agriculture practices are designed to achieve agricultural sustainability by implementation 
of sustainable management practices that minimize environmental degradation and conserve resources while maintaining highyielding profitable systems, and also improve the biological functions of the agro-ecosystem with limited mechanical practices and judicious use of external inputs. Globally innovations of conservation agriculture-based crop management technologies are proved to be more efficient in addressing the emerging problems (Gupta and Seth, 2007).

Compared to traditional agricultural practices, CA has several advantages in terms of saving up to $40 \%$ of time, labour and fuels (Hobbs et al., 2008), reduction in soil erosion, increased soil moisture conservation, lower surface runoff of herbicides and fertilizers, and improved profits (Chauhan et al., 2006). Further it is also beneficial in increasing the biological activity in soil as a consequence of the presence of crop residue and the lack of soil disturbance in CA. Conservation agriculture (CA) is being promoted as an alternative to conventional cropping practices for increasing crop yields and conserving soil resources. In spite of all these benefits the adoption of CA can't be widely popularized due to the serious threat posed by the weeds which are considered to be the major biological constraints in realizing the yield. Due to lack of tillage, weeds grow and flourish in CA if effective weed control measures are not taken.

\section{Weed dynamics in CA}

Weeds are considered to be major constraint in CA-based systems. The conventional tillage practices can control weeds effectively by uprooting and burying weeds deep into the soil thereby preventing the emergence of weed seeds by facilitating both vertical and horizontal movement of weed seeds. Several studies conducted to examine the direct and interactive effects of the three CA principles on weed dynamics (Giller et al., 2009; Farooq et al., 2011, Chauhan et al., 2012). Minimum soil disturbance which is one of the $3 \mathrm{CA}$ principles includes a range of tillage regimes affects the vertical weed seed distribution. It was reported that seeds infiltrate in soil very slowly in no tilled soil as compared to conventional tillage which in turn results in concentration of weed seeds that constitutes about $60-90 \%$ in the top $5 \mathrm{~cm}$ of soil surface (Swanton et al., 2000; Barberi et al., 2001). Hence a higher proportion of weed seeds germinate under no till condition. Thus reduction in tillage frequency or intensity affects the weed infestation which in turn causes differences in composition and relative time of emergence of weed species between CA system and conventional tillage system. This may be due to acceleration of germination and emergence of weeds by the type of equipment used in conventional tillage systems than by CT machinery. Further under CA system minimum soil disturbance favours the shift in weed species which was found to be infested with perennial weed species dominating over the annual weed species (Menalled et al., 2001; Taa et al., 2004). Conservation tillage may encourage these perennial reproductive structures present underground by not burying them to depths or by failing to uproot and kill them. However, predation of weed seeds and presence of nonviable seeds as a result of desiccation is found to be increased under no till conditions. Reduced tillage under CA system may also amplify the selection pressure of weed species whose life cycles and resource demands similar to that of the requirement of agronomic crops. The use of cover crops and crop residue in CA is beneficial in terms of conservation of soil moisture and moderation of soil temperature which indirectly influences the germination of both crop and weed seeds. However, the germination of weeds may be promoted in water limited environments than in wetter condition having little effect (Mashingaidez et al., 2012; 
Ngwira et al., 2014). At least 30\% of crop residue is maintained under CA system which may be beneficial in improving soil quality but not necessarily reduce weed germination and emergence (Liebman and Mohler, 2001). Though sometimes the residues indirectly reduce weed seed production by limiting weed growth via light interception, physical barriers, and allelopathy these may also advocate higher accumulation of weed seeds as a result of trapping of wind dispersed weed seeds (Tuesca et al., 2001). The timing of weed control measures therefore may be changed in order to ensure the effectiveness of maintenance of crop residue. Soil surface residues can interfere with the application of herbicides causing a greater likelihood of weed escapes if residue is not managed properly or herbicide application timings or rates are not adjusted. Weed control is a great challenge in adoption in CA than the conventional agriculture. The behaviour of weeds and their interaction with crops under $\mathrm{CA}$ tend to be complex and not fully understood. CA often causes weed shift resulting in increase in the density of certain weeds particularly those in which germination is not stimulated by light in addition to the perennial weeds. Hence, effective weed control techniques are needed to manage weeds successfully in CA. Weed species shifts and losses in crop yield as a result of increased weed density have been cited as major hurdles to the widespread adoption of CA. Crop yield losses in CA is mainly as a result of failure in controlling weed interference due to reduced tillage and may vary depending on weed dynamics and weed intensity. However, the recent development of post-emergence broad-spectrum herbicides provides an opportunity to control weeds in CA. Similar level of crop yield can be achieved from conservation tillage by effective control of weeds as that of conventional tillage (Mahajan et al., 2002). Herbicides are being widely used to control weeds in CA, but there is hardly any herbicide that can control different kinds of weeds with one or two applications. Furthermore, developing resistance in weeds, shifts in weed populations due to continuous use of a particular herbicide, less availability of new and effective herbicide molecules, increased cost of chemical control and environmental pollution related issues urges the need of going towards integrated weed management strategies to increase the sustainability of CA. Moreover, the viable weed seeds within the soil, will be reduced or managed easily with chemical controls but due to increased selection pressures initial weed control strategies have remained challenging for agricultural lands being switched to conservation tillage practices (Murphy et al., 2006; Swanton et al., 2008). Various approaches being employed to successfully manage weeds in CA systems include: preventive measures, cultural practices (tillage, crop residue as mulches, intercropping, cover cropping, competitive crop cultivars, planting geometry, sowing time, nutrient management etc.), use of herbicide-tolerant cultivars, and herbicides.

\section{Options for control of weeds}

\section{Preventive measures}

Preventing weed invasion in a field is first and the most important cheaper and easier option for management of weeds in general and especially under $\mathrm{CA}$ as the presence of even a small quantity of weed seeds may cause a serious infestation in the forthcoming seasons. Contamination during the time of crop harvesting is a common phenomenon if the crops and weeds are having similar duration. Major source of contamination involves weed seeds resembling the shape and size of crop seeds. Weedy rice or red rice is a perfect example, which spread in many Asian countries through the use of contaminated rice 
seeds. The aim should be to minimize the area of weed infestation and decrease the dissemination of weed seeds. Hand-rouging weeds before seed shed could be an important tactic in India in case of small farm size but has no feasibility in case of large farm.

The various preventive measures include: (i) using weed-free crop seed as far as possible, (ii) preventing the dissemination of weed seeds from one area to another, (iii) using well-decomposed manure/ compost to avoid presence of viable weed seeds, (iv) inspecting nursery to prevent transplanting of weed seedlings from nursery to main field, (v) removing weeds near irrigation canals and fence rows prior to flowering, (vi) mechanically cutting the reproductive part of weeds prior to seed setting, and (vii) implementing stringent Weed Quarantine Laws to prevent the entry of alien invasive and obnoxious weed seeds/propagules in the region.

\section{Cultural Practices}

\section{Adjustment of crop planting date}

Crop planting dates can be adjusted such that the crop emerges before the weeds for a competitive advantage or weeds are allowed to germinate and are controlled before or during crop planting. It was reported that planting earlier by even a few days can provide the crop a significant competitive advantage over weeds (Mohler, 2001c). For example, Adoption of NT allowed sowing of wheat crops 1-2 weeks earlier, thus helping the crop to establish before emergence of the still dormant Phalaris minor (Wall, 2007; Chauhan et al., 2012). However, models and field data generally show that unless weed infestations are severe, the crop can be planted later in order to control weeds early in the season which is counter-productive with respect to yield (Mohler, 2001d).

\section{Adjustment of crop density}

Crop density is an important component of the crop's ability to compete with weeds. Increasing the crop density provides the crop competitive advantages in using resources over weeds. The planting density suitable for maximum crop yield recommended based on weed free research environments, where crop biomass quickly increased followed by plateaus with higher planting densities. In the presence of weed competition, both models and field data suggest the relationship becomes more linear, with the benefit from increased planting density being greatest when weed densities are highest (Mohler, 2001c). Higher seeding rates are used in many crops to suppress weeds and these can be included as a component of weed management strategies in CA systems. The use of high seeding rates may not increase crop yield in weed-free environments, but their use in weedy or partially weedy environments has been found to reduce weed biomass and increase crop yield (Chauhan, 2011). While the goal of increased crop density to increase crop biomass may not always result insignificantly higher yields but it can be a potential tool for weed control tool in CA systems.

\section{Spatial arrangement of the crop}

It was found that the space occupied by weeds decreases as row spacing approaches intrarow spacing of plants, i.e. maximization of uniformity. Further random sowing of crop seeds doubles the ratio of weed to crop space compared to uniform planting and planting in clusters is the poorest design, allowing weeds to occupy a large amount of space (Colbach et al., 2014). The use of narrow row spacing gives an advantage to the crop by allowing faster canopy closure and less light penetration through the leaves, which helps in reducing weed competition. A narrow row 
spacing of $15 \mathrm{~cm}$ was reported to perform better in suppressing $P$. minor compared with the $23 \mathrm{~cm}$ spacing (Mahajan et al., 2004). Though the effectiveness of reduced row spacing on weed control depends on several other factors, including water limitations, nutrient placement, ratio between crop to weed height, and timing of emergence of crops and weeds, several recent studies have shown increased uniformity can help in reducing weed biomass as well as increasing yields in a variety of crops (Weiner et al., 2001; Olsen et al., 2012; Marin and Weiner, 2014).

\section{Water and nutrient management}

Weeds have generally more aggressive uptake of resources such as nutrients, water as compared to crops. Therefore altering timing, placement, and source of fertilizer to preferentially provide the crop better accessibility to nutrients is desirable. Banding of fertilizers can reduce weed biomass compared to broadcasting and deep banding is found to be more effective than surface banding (Derksen et al., 2002). The source of fertilizer also reported to favour certain weeds thus making a shift in weed species (Liebman and Mohler, 2001).

Irrigation is considered to be important for weed control through spatial and temporal variation of soil moisture. It was reported that by sowing large-seeded crops into deep soil moisture when upper surface is dry can provide crops with an initial advantage over weeds (Liebman and Mohler, 2001). Water management has been an important component of weed control in conventionally flooded CT-PTR, in which the emergence and growth of most of weeds of rice is inhibited by submerging the field after seeding. Whereas in ZT-DSR, weed management is difficult due to emergence of weeds (Chauhan 2012). The development of rice cultivars capable of germinating under anaerobic conditions would greatly facilitate weed management via flooding in DSR.

\section{Cultivar selection}

Certain varieties have been reported to be more competitive with weeds than others (Mohler, 2001c; Marin and Weiner, 2014). Also the role of CA-specific cultivars for weed competitiveness under CA conditions is an active area of research (Mahajan and Chauhan, 2013). Designing breeding programs to select for competitive ability under $\mathrm{CA}$ is challenging due to the complexity of characteristics and large variation between location and year, but development of such varieties would be highly beneficial not only for weed control but for other CA-specific characteristics (Herrera et al., 2013). Traditional and tall cultivars are often more weed-competitive, but they produce lower yields than shortstatured modern cultivars. In general, it has been observed that early maturing inbred and hybrids because of their faster early growth and ground cover are more effective in smothering weeds than medium- to longduration cultivars (Gill et al., 2013, Singh et al., 2014). Under delayed sowing conditions, ' $P B W-343$ ' was superior to other cultivars against $P$. minor whereas they are equally competitive under timely sown condition (Kaur et al., 2003). Breeding competitive cultivars with importing allelopathic traits from their wild relatives is a potential technique for improving the weedcompetitive ability of commercial cultivars. There is a need to develop weed-competitive cultivars, keeping in mind that both shoot and root traits as far as nutrient uptake considered in crop-weed interactions. In case of selective herbicides, herbicide-tolerant crops may facilitate adoption of no-till practices (Givens et al., 2009) but may also restrict crop rotations (Alister and Kogan, 
2005).Herbicide-tolerant crops must be used in conjunction with other weed control methods, particularly rotational use of herbicidal mode of actions to avoid resistance issues. Herbicides though considered to be useful tool in weed control in CA poses certain limitation regarding its use due to the potential development of resistance, their limited availability and other health related issue.

\section{Retention of crop residue}

One of the pillars of CA is retention of residue cover on the soil surface which plays an important role in suppressing emergence and growth of many weed species besides its role in moisture and soil conservation. However, the extent of suppression depends on the quantity and type of crop residue (Chauhan et al., 2006). For example, in cereal crops and crops grown in an irrigated area, more residues can be obtained than other crops such as pulses, oilseeds and crops grown in dry land area. Growing a cover crop between two main crops may also help in reducing weed seed bank and weed population in CA systems.

The cover crop is then killed using a nonselective herbicide. The dead mulch of the cover crop suppresses weed germination and emergence by releasing allelochemicals as well as by reducing light availability to the weed seeds. The presence of residue not only reduces weed seedling emergence, but may also delay or prolong seedling emergence (Chauhan, 2010). The late-emerging seedlings may be less competitive to crops and may have less effect on crop yield. Zero tillage in combination with residue retention on the surface and early sowing results in the suppression of $P$. minor and other weeds of wheat. Improvement in planting technology like Turbo Happy seeder has made it possible to sow wheat in heavy residue mulch of up to
8 to 10 t/ha without any adverse effects on crop establishment (Sharma et al., 2008, Kumar and Ladha 2011). Further Singh et al., (2013) recorded 48\% reduction in weed population in wheat sown with 'Turbo Happy seeder' as compared to conventional till sown wheat. There is a need to invest in research and development to bring affordable machines capable of sowing in loose residue.

\section{Crop rotation}

Growing a single crop or crops under similar management practices allows some weed species to become dominant in the system. Rotation of crops with different management practices, on the other hand, disturbs the growing cycle of weeds and prevents build-up of problematic weeds. It also allows farmers to use different herbicides to control problematic weeds. Diversification and intensification of the RW system by growing a short duration vegetable crop (pea or potato) followed by late sown wheat can also improve weed control without increasing herbicide use (Chhokar et al., 2008). Rotation designs involving four years or more have been found to drastically reduce herbicide use in both tilled and untilled systems (Anderson, 2008; Liebman et al., 2008).

Changing the timing of activities or alternating between early and late maturing cultivars may control the infestations of weed species if rotation is not found feasible. A relatively new rotation schedule called as 'stacked rotations', in which rotated crops are grown for two consecutive years before rotating. Stacking may involve identical crops or crops with similar growth cycles. The stacked rotation designs offer superior weed control compared to yearly rotations as reported by Anderson (2005). By following stacked rotations, weeds are forced through one crop's selection pressure for some years followed by a break. 


\section{Stale seed bed technique}

The use of stale seedbed technique can significantly reduce weed density in a crop in CA systems. Due to lack of soil disturbance, most of the weed seeds tend to concentrate on the soil surface in CA system as a result of which a flush of weed seedlings appears within a week after irrigation. In the stale seedbed practice, a light irrigation is given to stimulate germination of these weed seeds after which the weed seedlings emerged can be killed using a nonselective herbicide (e.g. glyphosate or paraquat). Stale seedbed significantly reduced weed pressure in ZTwheat (Mahajan et al., 1999).

This practice helps in reducing the weed seed bank size in the soil thus facilitating the emergence of crops in a relatively weed free environment. Some of the weed species sensitive to the stale seedbed technique are Cyperus iria, Digitaria ciliaris, Echinochloa colona, Eclipta prostrata, Leptochloa chinensis, Ludwigia hyssopifolia and Portulaca oleracea.

The fallow period (45-60 d) between wheat harvest and the sowing of rice provides an excellent opportunity to implement stale seed bed for weed management before planting DSR which encourages the emergence of crop under weed-free conditions providing competitive advantage over late-emerging weed seedlings. With the limited options available to manage weedy rice in ZT-DSR, this technique is recommended as part of an IWM strategy in many weedy rice-infested areas (Rao et al., 2007).

\section{Laser land levelling}

Laser land leveling is an integral component of $\mathrm{CA}$ as it provides uniform moisture distribution to the entire field which in turn facilitates uniform crop stand and growth, leading to lesser weed infestation whereas unleveled fields frequently exhibit patchy growth of crops. The areas with sparse plant populations are zones of higher weed infestation. Weed management in laser leveled field is relatively easier and requires less labour and time for manual weeding operation due to lesser weed infestation than unleveled one. A reduction of $75 \%$ in labour requirement for weeding operation can be possible due to precision land leveling. Reduction in weed population in wheat after 30 DAS was recorded under precisely leveled fields in comparison to traditional leveled fields (Jat et al., 2009).

\section{Establishment methods}

Zero-till rice can be grown either by direct seeding (ZT-DSR) or by transplanting (ZTTPR) rice seedlings manually or mechanically. Kumar et al., (2013) reported the yield losses due to weeds were $90 \%$ under ZT-DSR, compared with 35 to $42 \%$ under ZT-TPR without any weed control measures. Since DSR has a preference for saving labor and water resources, it can be rotated with ZT transplanted rice every few years to keep weed pressure under check. Under herbicides and integrated weed management (IWM) treatments, ZT-DSR recorded grain yield similar to CT-DSR and CT-PTR at Ludhiana (AICRP-WM 2014).Among DSR methods, under IWM, ZT-DSR with residue retention on the surface recorded 19\% higher yield than CT-DSR, whereas under herbicides treatment, CT-DSR recorded $8 \%$ higher yield than ZTDSR.

The succeeding wheat crop, sown with either CT or ZT with and without residues retention on the surface reported to have similar grain yield. Planting wheat on raised beds reduced weed density and biomass as compared to the conventional method of flat seedbed (Dhillon et al., 2005). 


\section{Microbial weed control}

Microorganisms offer a huge, largely untapped resource for bio-control of weeds (Kennedy, 1999). Hundreds of microorganisms reported to have potential for biological weed control including bacteria, fungi, and actinomycetes (Li et al., 2003).The commercial development of those microorganisms having ability to suppress the growth of many common weeds is still under research.(Stubbs and Kennedy, 2012) Although the optimal method of application of these bio-controls is still a matter of research, application of microbial bio-control can be a promising method to compliment weed control in CA.

\section{Use of herbicides}

Herbicide use is an important component of weed management and choosing an appropriate herbicide and timing of its application is critical in CA systems. Weeds present before crop sowing are killed by using non-selective herbicides. Due to presence of residue, pre emergence herbicides may not work effectively in CA farming as straw or residue might intercept a considerable amount of soil-active herbicides about $15-80 \%$ of the applied herbicides (Chauhan et al., 2012). There is a need to better understand the interaction effects of pre-emergence herbicides and residue on weed control. Due to less opportunity of using a pre-emergence herbicide in CA, timing of post-emergence herbicides is critical to avoid any yield loss due to weed competition. There is a need to rotate herbicides with different modes of action and to mix different herbicides to achieve effective weed control. Herbicide mixtures should be used to delay the development of resistance in weeds and improve the weed control spectrum. However, for the sustenance of CA systems, herbicide rotation and/or integration of weed management practices is preferable as continuous use of a single herbicide over a long period of time may result in the development of resistant biotypes, shifts in weed flora, and negative effects on the succeeding crop and environment. In CA, the diverse weed flora that came up in the field after harvesting of preceding crop must be killed by using non-selective herbicides like glyphosate, paraquat or ammoniumglufosinate.

Some crop cultivars resistant to nonselective herbicides are available and may prove to be a useful tool in managing weeds in CA systems. They give farmers the flexibility to apply herbicides only when needed, to control total input of herbicides and to use herbicides with preferred environmental characteristics thereby facilitating easier control of weeds. However, herbicide tolerant crop cultivars should not be considered as a stand-alone component of weed management. An integrated weed management strategy should be used to ensure that this important weed management tool remains profitable and environmentally sound over a long period of time.

\section{Integrated weed management}

Considering the diversity of weed problems, no single method of weed control, viz. cultural, mechanical or chemical could provide the desired level of weed control efficiency under CA.

To maintain sustainability of CA systems, there is a need to integrate different weedmanagement strategies for widening the weed control spectrum and efficacy for sustainable crop production. For example, planting a weed-competitive cultivar in narrow rows with high seeding rates and use of residue as mulch and an effective post-emergence herbicide may manage weeds effectively in 
CA systems. Integrated use of narrow row spacing $(15 \mathrm{~cm})$, higher seed rate $(150 \mathrm{~kg} / \mathrm{ha})$ and $25 \%$ lower dose of clodinafop reduced $P$. minor density compared with normal spacing $(22.5 \mathrm{~cm})$, normal seed rate $(125 \mathrm{~kg} / \mathrm{ha})$ and field dose of clodinafop (Bhullar and Walia, 2004). Integrated strategies will also ensure that herbicide use remains profitable and environmentally sound over a long period of time. Weeds of secondary importance may emerge as a primary weed problem because of the continuous use of a single herbicide or herbicides with a similar mode of action. This problem can be avoided by adopting an integrated approach that includes herbicide rotation, herbicide combinations and crop rotation to develop sustainable and effective weed management strategies under $\mathrm{CA}$ systems.

It is possible to achieve the same or even higher yield with $\mathrm{CA}$ as with conventional tillage if the weeds are controlled efficiently. The practices of CA particularly crop rotation and surface residue retention, are themselves methods of weed control. The combined use of all three principles can offer disproportionate advantages, and weed problems are more likely to occur if one of them used. For CA, the synergistic effects of utilizing multiple control tactics are even more crucial. With respect to weed control, NT should never be implemented in monoculture systems and vice versa. Additional options for weed control in CA systems may include selecting new varieties with more competitive crop canopies; altering crop planting dates, planting densities, rowspacing and/or fertilizer placement; utilizing microbial weed controls; and implementing long rotations designed with weed management in mind. Integrated weed management system is not meant for replacing selective, safe and efficient herbicides but involves a sound strategy to encourage judicious use of herbicides along with other safe, effective, economical and eco-friendly control measures. The use of clean crop seeds and seeders and field sanitation combining with good agronomic practices, timeliness of operations, fertilizer and water management, and retaining crop residues on the soil surface improve the weed control efficiency of applied herbicides and competitiveness against weeds. Approaches such as stale seedbed practice, uniform and dense crop establishment, use of cover crops and crop residues as mulch, crop rotations, and practices for enhanced crop competitiveness with a combination of preand post-emergence herbicides should be integrated to develop sustainable and effective weed management strategies under CA systems.

\section{Future research need}

Understanding weed dynamics, their interference potential and suitable management practices with low-cost herbicides in CA further required. The effects of different crop residue mulches on different weeds and how much residue of these crops is required to achieve optimum suppression of different weeds and short to long term effects of inclusion of cover crops should be studied extensively. Few breeding programs are actively developing cultivars specifically for the CA environment, although initial work appears promising. So it should be further enhanced to develop weed competitive crop cultivars. Estimation of season-long seed predation potential under conventional and conservation agriculture and mechanisms by which seed predation can be enhanced and Development of management strategies for emerging problematic weed species should be encouraged. Further research is needed concerning interactions between CA practices with regard to weed control, particularly tillage and residue retention. Models are increasingly being used to explore cropping 
systems scenarios and their predicted effects on weed populations which could be a valuable tool for investigating the effects of $\mathrm{CA}$ in various environments. Developing a standardized template for data collection could offer further insights into weed responses to $\mathrm{CA}$ adoption. Exploring the weed-suppressive potential of stacked and longer-term crop rotations is another promising area that has received little attention.

\section{References}

AICRP-WM. 2014. Annual Technical Report. All India Coordinated Research Project on Weed Management-2014. Department of Agronomy, Punjab Agricultural University, Ludhiana, India, $100 \mathrm{p}$.

Alister, C., Kogan, M. 2005. Efficacy of imidazolinone herbicides applied to imidazolinone-resistant maize and their carryover effect on rotational crops. Crop Prot. 24, 375-379.

Anderson, R.L. 2005. A multi-tactic approach to manage weed population dynamics in crop rotations. Agron. J. 97.1579-1583.

Anderson, R.L. 2008. Diversity and no-till: keys for pest management in the U.S. Great Plains. Weed Sci. 56. 141-145.

Barberi, P., Bonari, E., Mazzoncini, M., García-Torres, L., Benites, J., MartínezVilela, A. (Vol. 2: offered contributions, XUL) 2001. Weed density and composition in winter wheat as influenced by tillage systems. Conservation agriculture, a worldwide challenge. In: Proceedings of the First World Congress on Conservation Agriculture, Madrid, Spain, 1-5 October, pp. 451-455.

Bhullar, M.S., Walia, U.S. 2004. Effect of seed rate and row spacing on the efficacy of clodinafop for combating isoproturon resistant Phalaris minor
Retz. in wheat. Plant Protection Quarterly. 19(4): 143-46.

Chauhan, B. S., Gill, G., Preston, C.2006 Aust. J. Exp. Agric. 46. 1557-1570.

Chauhan, B. S., Johnson, D. E. 2010. Adv. Agron., 2010, 105: 221-262.

Chauhan, B.S., Johnson, D.E. 2011. Row spacing and weed control timing affect yield of aerobic rice. Field Crops Research. 121. 226-231.

Chauhan, B.S., Singh, R.G., Mahajan, G. 2012. Ecology and management of weeds under conservation agriculture: a review. Crop Prot. 38.57-65.

Chauhan, B.S., Singh, V.P., Kumar, A., Johnson, D.E. 2011. Relations of rice seeding rates to crop and weed growth in aerobic rice. Field Crops Research. 121.105-115.

Chhokar, R.S, Sharma, R.K., Singh, R.K., Gill, S.C. 2008. Herbicide resistance in little seed canarygrass (Phalaris minor) and its management. p. 106. In: Proceedings of 14th Australian Agronomy Conference Adelaide, South Australia.

Colbach, N., Collard, A., Guyot, S.H., Meziere, D., Munier-Jolain, N.2014. Assessing innovative sowing patterns for integrated weed management with a 3D crop: weed competition model. Eur. J. Agron. 53: 74-89.

Derksen, D.A., Anderson, R.L., Blackshaw, R.E., Maxwell, B. 2002. Weed dynamics and management strategies for cropping systems in the northern Great Plains. Agron. J. 94: 174-185.

Dhillon, S.S., Prashar, A., Thaman, S. 2005. Comparative studies on the effect of weed management practices on Phalaris minor in bed and conventionally planted wheat (Triticum aestivum L.). Indian Journal of Ecology. 32: 72-75.

Farooq, M., Flower, K., Jabran, K., Wahid, A., Siddique, K.H. 2011. Crop yield andweed management in rainfed 
conservation agriculture. Soil Tillage Res. 117: 172-183.

Gill,G., Bhullar, M.S., Yadav, A., Yadav, D.B. 2013. Technology for Successful Production of Direct Seeded Rice. p. 32. In: A training manual based on the outputs of ACIAR (Australian Centre for International Agricultural Research) funded project CSE/2004/033. A joint Publication of University of Adelaide, South Australia; P.A.U. Ludhiana, Punjab; CCS H.A.U., Hissar, Haryana.

Giller, K.E., Witter, E., Corbeels, M., Tittonell, P. 2009. Conservation agriculture and small holder farming in Africa: the heretics' view. Field Crops Res. 114. 23-34.

Givens, W.A., Shaw, D.R., Kruger, G.R., Johnson, W.G., Weller, S.C., Young, B.G., Wilson, R.G., Owen, M.D., Jordan, D. 2009. Survey of tillage trends following the adoption of glyphosate-resistant crops. Weed Technol. 23. 150-155.

Gupta, R.K., Seth, A. 2007. A review of resource conserving technologies for sustainable management of the ricewheat cropping systems of the IndoGangetic Plains (IGP). Crop Protection. 26. 436-447.

Herrera, J., Verhulst, N., Trethowan, R., Stamp, P., Govaerts, B. 2013. Insights into genotype $\times$ tillage interaction effects on the grain yield of wheat and maize. Crop Sci. 53. 1845-1859.

Hobbs, P. R., Sayre, K., Gupta, R. 2008.Philos. Trans. R. Soc. London, Ser. B., 363. 543-555.

Jat, M., Gathala, M.L., Ladha, J.K., Saharawat, Y.S., Jat, A.S., Kumar, V., Sharma, S.K., Kumar, V., Gupta, R. 2009. Evaluation of precision land leveling and double zero-till systems in rice-wheat rotation: water use, productivity, profitability and soil physical properties. Soil and Tillage
Research. 105. 112-121.

Kaur, H., Brar, H.S., Walia, U.S. 2003. Competitive ability of wheat cultivars sown on different dates with littleseed canarygrass (Phalaris minor Retz.). Indian Journal Weed Science. 35.21-23.

Kennedy, A.1999. Soil microorganisms for weed management. J. Crop Prod. 2.123-138.

Kumar, V., Ladha, J.K. 2011. Direct seeding of rice: recent developments and future research needs. Advances in Agronomy. 111. 299-413.

Kumar, V., Singh, S., Chhokar, S., Ram, K., Malik, S., Daniel, C., Ladha, J.K. 2013. Weed management strategies to reduce herbicide use in zero-till rice-wheat cropping systems of the IGP. Weed Technology, 27. 241-254.

Li, Y., Sun, Z., Zhuang, X., Xu, L., Chen, S., Li, M.2003. Research progress on microbial herbicides. Crop Protect., 22. 247-252.

Liebman, M., Gibson, L.R., Sundberg, D.N., Heggenstaller, A.H., Westerman, P.R., Chase, C.A., Hartzler, R.G., Menalled, F.D., Davis, A.S., Dixon, P.M. 2008.Agronomic and economic performance characteristics of conventional and low-external-input cropping systems in the central corn belt. Agron. J. 100,600-610.

Liebman, M., Mohler, C.L., 2001. Ecological Management of Agricultural Weeds, Pp. 210-269.

Mahajan, G., Brar, L. S., Sardana, V.2004. Indian J. Weed Sci. 36. 166-170.

Mahajan, G., Brar, L.S., Sardana, V. 1999. Effect of tillage and time of sowing on the efficacy of herbicides against Phalaris minor in wheat. pp. 193-198. In: Proceedings 17th APWSS Conference, Bangkok, Thialand.

Mahajan, G., Brar, L.S., Walia, U.S. 2002. Phalaris minor response in wheat in relation to planting dates, tillage and 
herbicides. Indian Journal of Weed Science. 34. 213- 215.

Mahajan, G., Chauhan, B.S. 2013. The role of cultivars in managing weeds in dryseeded rice production systems. Crop Prot. 49. 52-57.

Marin, C., Weiner, J. 2014. Effects of density and sowing pattern on weed suppression and grain yield in three varieties of maize under high weedpressure. Weed Res. 54. 467-474.

Mashingaidze, N., Madakadze, C., Twomlow, S., Nyamangara, J., Hove, L. 2012.Crop yield and weed growth under conservation agriculture in semiarid Zimbabwe. Soil Tillage Res. 124. 102110.

Menalled, F.D., Gross, K.L., Hammond, M. 2001. Weed aboveground and seed bank community responses to agricultural management systems. Ecol. Appl. 11.1586-1601.

Mohler, C. 2001c. Ecological Management of Agricultural Weeds, 269-321.

Mohler, C. 2001d. Ecological Management of Agricultural Weeds, 139-209.

Murphy, S.D., Clements D.R., Belaoussoff S., Kevan P.G., Swanton, S. J. 2006. Promotion of weed species diversity and reduction of weed seed banks with conservation tillage and crop rotation. Weed Science. 54. 69-77.

Ngwira, A., Aune, J.B., Thierfelder, C.2014. On-farm evaluation of the efffects of theprinciples and components of conservation agriculture on maize yield andweed biomass in Malawi. Exp. Agric. 50. 591-610.

Olsen, J.M., Griepentrog, H.-W., Nielsen, J., Weiner, J. 2012. How important are crop spatial pattern and density for weed suppression by spring wheat. WeedSci. 60. 501-509.

Rao, A.N., Johnson, D.E., Sivaprasad, B., Ladha, J.K., Mortimer, A.M. 2007. Weed management in direct-seeded rice. Advances in Agronomy. 93. 153255.

Sharma, K.L., Grace, K., Mandal, J., Gajbhiye, P.N., Korwar, S.K., Ramesh, G., Ramachandran, V.K., Yadav, S.K. 2008. Evaluation of long-term soil management practices through key indicators and soil quality indices using principal component analysis and linear scoring technique in rainfed Alfisols. Australian Journal of Soil Research. 46. 368-377.

Singh, A., Kang, J.S., Kaur, M., Goel. A. 2013. Root parameters, weeds, economics and productivity of wheat (Triticum aestivum) as affected by methods of planting in-situ paddy straw International Journal of Current Microbiology and Applied Sciences. 2(10): 396-405.

Singh, R.K., Singh, A., Pandey, C.B. 2014 Agro-biodiversity in rice-wheat-based agro ecosystems of eastern Uttar Pradesh, India: Implications for conservation and sustainable management. International Journal of Sustainable Development \& World Ecology. 21. 46-59.

Singh, S., Ladha, J.K., Gupta, R.K., Bhusan, L., Rao, A.N., Sivaprasad, B., Singh, P.P. 2007. Evaluation of mulching, intercropping with Sesbania and herbicide use for weed management in dry-seeded rice (Oryza sativa L.). Crop Protection. 26. 518- 524.

Stubbs, T.L., Kennedy, A.C. 2012. Microbial Weed Control And Microbial Herbicides. INTECH Open Access Publisher.

Swanton, C.J., Mahoney, K.J., Chandler, K., Gulden, R.H. 2008. Integrated weed management: Knowledge-based weed management systems. Weed Science. 56. $168-172$.

Swanton, C.J., Shrestha, A., Knezevic, S.Z., Roy, R.C., Ball-Coelho, B.R. 2000. 
Influence of tillage type on vertical weed seed bank distribution in a sandy soil. Canadian Journal of Plant Science. 80. 455-457.

Taa, A., Tanner, D., Bennie, A.T. 2004. Effects of stubble management, tillage and cropping sequence on wheat production in the south-eastern highlands of Ethiopia. Soil Tillage Res. 76. 69-82.

Tuesca, D., Puricelli, E., Papa, J. 2001. A long-term study of weed flora shifts indifferent tillage systems. Weed Res.
41. 369-382.

Wall, P.C. 2007. Tailoring conservation agriculture to the needs of small farmers' in developing countries: an analysis of issues. J. Crop Improv. 19. 137-155.

Weiner, J., Griepentrog, H.W., Kristensen, L.2001. Suppression of weeds by spring wheat Triticum aestivum increases with crop density and spatial uniformity. $J$. Appl. Ecol. 38. 784-790.

\section{How to cite this article:}

Twinkle Jena and Babu Lal Meena. 2017. Weed Management Options in Conservation Agriculture. Int.J.Curr.Microbiol.App.Sci. 6(12): 1232-1244.

doi: https://doi.org/10.20546/ijcmas.2017.612.139 